\title{
The cathodic reduction of oxygen at metal tetrasulfonato- phthalocyanines : influence of adsorption conditions on electrocatalysis
}

\author{
Citation for published version (APA): \\ Elzing, A., Putten, van der, A. M. T. P., Visscher, W., \& Barendrecht, E. (1987). The cathodic reduction of \\ oxygen at metal tetrasulfonato-phthalocyanines : influence of adsorption conditions on electrocatalysis. Journal \\ of Electroanalytical Chemistry and Interfacial Electrochemistry, 233(1-2), 99-112. https://doi.org/10.1016/0022- \\ 0728(87)85009-X
}

DOI:

10.1016/0022-0728(87)85009-X

Document status and date:

Published: 01/01/1987

\section{Document Version:}

Publisher's PDF, also known as Version of Record (includes final page, issue and volume numbers)

\section{Please check the document version of this publication:}

- A submitted manuscript is the version of the article upon submission and before peer-review. There can be important differences between the submitted version and the official published version of record. People interested in the research are advised to contact the author for the final version of the publication, or visit the DOI to the publisher's website.

- The final author version and the galley proof are versions of the publication after peer review.

- The final published version features the final layout of the paper including the volume, issue and page numbers.

Link to publication

\footnotetext{
General rights

- You may freely distribute the URL identifying the publication in the public portal. follow below link for the End User Agreement:

www.tue.nl/taverne

\section{Take down policy}

If you believe that this document breaches copyright please contact us at:

openaccess@tue.nl

providing details and we will investigate your claim.
}

Copyright and moral rights for the publications made accessible in the public portal are retained by the authors and/or other copyright owners and it is a condition of accessing publications that users recognise and abide by the legal requirements associated with these rights.

- Users may download and print one copy of any publication from the public portal for the purpose of private study or research.

- You may not further distribute the material or use it for any profit-making activity or commercial gain

If the publication is distributed under the terms of Article $25 \mathrm{fa}$ of the Dutch Copyright Act, indicated by the "Taverne" license above, please 
J. Electroanal. Chem, 233 (1987) 99-112

Elsevier Sequoia S.A., Lausanne - Printed in The Netherlands

\title{
THE CATHODIC REDUCTION OF OXYGEN AT METAL TETRASULFONATO-PHTHALOCYANINES: INFLUENCE OF ADSORPTION CONDITIONS ON ELECTROCATALYSIS
}

\author{
A. ELZING, A. VAN DER PUTTEN, W. VISSCHER and E. BARENDRECHT \\ Laboratory for Electrochemistry, Department of Chemical Technology, Eindhoven University of Technology, \\ P.O. Box 513, $5600 \mathrm{MB}$ Eindhoven (The Netherlands)
}

(Received 10th June 1986; in revised form Sth February 1987)

\begin{abstract}
Some conditions which promote the adsorption of tetrasulfonato-phthalocyanines on pyrolytic graphite are formulated. As a consequence of one of these, the ionic strength, aggregation in the solution is postulated to occur in order to explain some observations made by UV-vis spectroscopy and the formation of a deposit in $1 M \mathrm{KOH}$ solutions.

A model based on "surface diffusion" is presented to explain the observed "kinetic limitation" for electrodes with a low coverage of cobalt tetrasulfonato-phthalocyanine (CoTSPc), without the introduction of a rate-determining chemical step. When applied to FeTSPc, the same model leads to the conclusion that dimers of FeTSPc are present on the graphite surface.

The difference in behaviour between FeTSPe and FePc (iron phthalocyanine) is discussed.
\end{abstract}

\section{INTRODUCTION}

Oxygen reduction at electrodes prepared by irreversible adsorption of metal chelates on graphite has been described in a number of papers [1-8]. It was discovered more or less accidently that electrodes that had been used in an electrolyte in which a water-soluble porphyrin or phthalocyanine was dissolved showed the same oxygen reduction behaviour when they were thereafter investigated in the electrolyte free of dissolved metal chelate [7,9]. So, the adsorption of these complexes is so strong that measurements in electrolytes devoid of the metal chelate are possible, without desorption of the complex on the time scale of the experiment. The way in which the molecules are adsorbed on the surface is not completely understood $[8,10,11]$. Also, the conditions which affect the establishment of the adsorption equilibrium are not fully known. In some cases, the adsorption is a fast process, while in other cases adsorption occurred only as the result of cycling the electrode for half an hour in a solution of the complex $[8,12]$. 
To obtain more insight into the adsorption phenomena, we have investigated the adsorption process in more detail and also the effect of ageing on phthalocyanine solutions. The first question was: under which conditions can the highest coverage of cobalt or iron tetrasulfonato-phthalocyanine (CoTSPc or FeTSPc) on pyrolytic graphite $(\mathrm{Cp})$ be obtained? For comparison, cobalt and iron phthalocyanine (CoPc or $\mathrm{FePc}$ ) were also investigated. Subsequently, the effect of different coverages on the oxygen reduction was studied. In addition, UV-vis spectra were recorded to determine the reaction of the water-soluble phthalocyanines with oxygen. It is generally accepted that peroxy species are formed [13-15]:

(Co-O-O-Co; $\mathrm{Fe}-\mathrm{O}-\mathrm{O}-\mathrm{Fe}$ )

For FePc, even the subsequent formation of an oxo-bridged species has been reported $[16,17]$ :

$(\mathrm{Fe}-\mathrm{O}-\mathrm{Fe})$

However, an oxo-bridged dimer has never been reported for $\operatorname{CoPc}[17,18]$.

In our experiments, we concentrated our attention on the oxygenation behaviour of aged phthalocyanine solutions.

\section{EXPERIMENTAL}

CoTSPc and FeTSPc were synthesized as described by Weber and Busch [19]. The chemicals CoPc and FePc were obtained from Eastman Kodak and used as such. Pyridine was used as the solvent for $\mathrm{CoPc}$ and FePc, while twice-distilled water was used for the tetrasulfonated form.

To determine the solution species in the case of the water-soluble complexes, UV-vis spectra were recorded using a double beam Pye-Unicam spectrophotometer. The spectra were recorded in oxygen- or helium-saturated solutions. Traces of oxygen were removed from the helium by passing the gas over a BTS-copper type catalyst (obtained from BASF) at a temperature of $150^{\circ} \mathrm{C}$. Preliminary experiments showed that at room temperature the reaction with oxygen is slow. For this reason, the spectra were recorded at $70^{\circ} \mathrm{C}$.

All electrochemical experiments were performed in a standard three-compartment electrochemical cell. In the case of cyclic voltammetry, oxygen was removed from the electrolyte, $1 \mathrm{M} \mathrm{KOH}$, by bubbling nitrogen through it. Oxygen reduction was measured with the rotating-disc electrode technique in the same, but now oxygen-saturated, electrolyte. A Tacussel bipotentiostat was used.

The working electrode was a disc electrode made of $\mathrm{Cp}$, with a surface area of $0.52 \mathrm{~cm}^{2}$. The electrode was polished with $0.3 \mu \mathrm{m}$ alumina before use to obtain a flat surface free from adsorbed species. The alumina was removed from the disc by cleaning in an ultrasonic bath for $1 \mathrm{~min}$ or by rinsing in a powerful stream of water. No difference was observed in the two procedures. The complexes were applied to the disc by dipping the polished electrode for $1 \mathrm{~min}$ into a solution of the corresponding complex and thereafter flushing with distilled water. A reversible Pt 
hydrogen electrode (RHE) was used, to which all potentials are referred. The counter-electrode was made of a $\mathrm{Pt}$ foil.

\section{RESULTS AND DISCUSSION}

\section{(A) The adsorption process}

For the description of the adsorption process the following experiments are relevant.

The difference between CoTSPc and FeTSPc

From a freshly prepared $10^{-4} \mathrm{M}$ solution of CoTSPc in distilled water, adsorption of CoTSPc on graphite is possible in $1 \mathrm{~min}$ or less. The presence of CoTSPc on graphite is indicated by the redox peaks in the cyclic voltammogram (Fig. 1). For FeTSPc, no adsorption is observed under these conditions. Adsorption of the latter could be achieved only by adding a salt like $\mathrm{LiClO}_{4}$, a base $(\mathrm{KOH})$ or an acid $\left(\mathrm{H}_{2} \mathrm{SO}_{4}\right)$ to the solution (Fig. 2). If the concentration of one of these supporting electrolytes is increased, then the coverage of FeTSPc also increases; for a concentration of $1 M$, a saturation value for the coverage is obtained. Therefore, all the solutions used for the achievement of the adsorption of FeTSPc were prepared from $1 M \mathrm{KOH}$. However, for CoTSPc no effect of the type or concentration of the supporting electrolyte was observed.

\section{Crystallization in the presence of ions}

CoTSPc is soluble in $1 M \mathrm{KOH}$. After a few days, however, small crystals are observed in the solution and the colour changes gradually from dark blue to green. After 1 week, a deposit is formed and the colour of the solution is now light green. If the deposit is dissolved in distilled water, the original CoTSPc spectrum is obtained anew. The light green colour of the remaining solution is probably caused by an impurity or by some degradation of the complex. A CoTSPc solution in
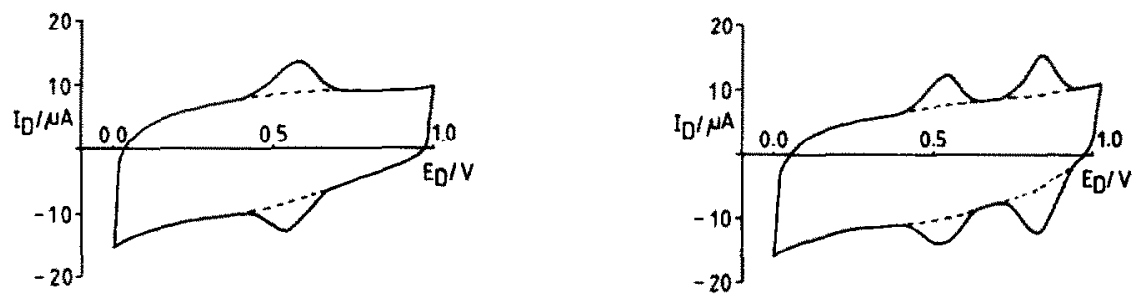

Fig. 1. Cyclic voltammogram of CoTSPc adsorbed on $\mathrm{Cp}$ from a $10^{-4} M$ solution. The dashed curve is for Cp only. Electrolyte: $1 M \mathrm{KOH}$, oxygen-free; $\operatorname{scan}$ rate $=100 \mathrm{mV} \mathrm{s}^{-1}$.

Fig. 2. Cyclic voltammogram of FeTSPc adsorbed on $\mathrm{Cp}$ from a $10^{-4} M$ solution in $1 M \mathrm{KOH}$. Other specifications as in Fig. 1. 
distilled water is stable for months; it still retains its blue colour. FeTSPc shows the same behaviour.

\section{Irreversible oxygenation}

A freshly prepared solution of CoTSPc (ca. $10^{-5} M$ ) in oxygen-free $0.1 \mathrm{M} \mathrm{KOH}$ shows the spectrum depicted by the solid curve in Fig. 3A. This spectrum was recorded immediately after the addition of CoTSPc to the oxygen-free $0.1 \mathrm{M} \mathrm{KOH}$ solution. Two peaks are visible and are ascribed to a monomer $(670 \mathrm{~nm})$ and a dimer species $(626 \mathrm{~nm})[14,15]$.

When oxygen is bubbled through the solution for $1 \mathrm{~h}$, a new peak appears at a wavelength of $670 \mathrm{~nm}$; this peak has been ascribed to a peroxy-bridged dimer (Fig. $3 A)[14,15]$. This figure also shows that after helium saturation the original spectrum is not restored. If shorter times for oxygen and helium saturation are used, a more reversible oxygenation is observed. However, for longer times, a few hours and more, and depending on the measuring temperature, the oxygenation is quite irreversible. This means that the spectra of the oxygen-free species could not be converted into the spectra of the oxygen-containing species and vice versa with the
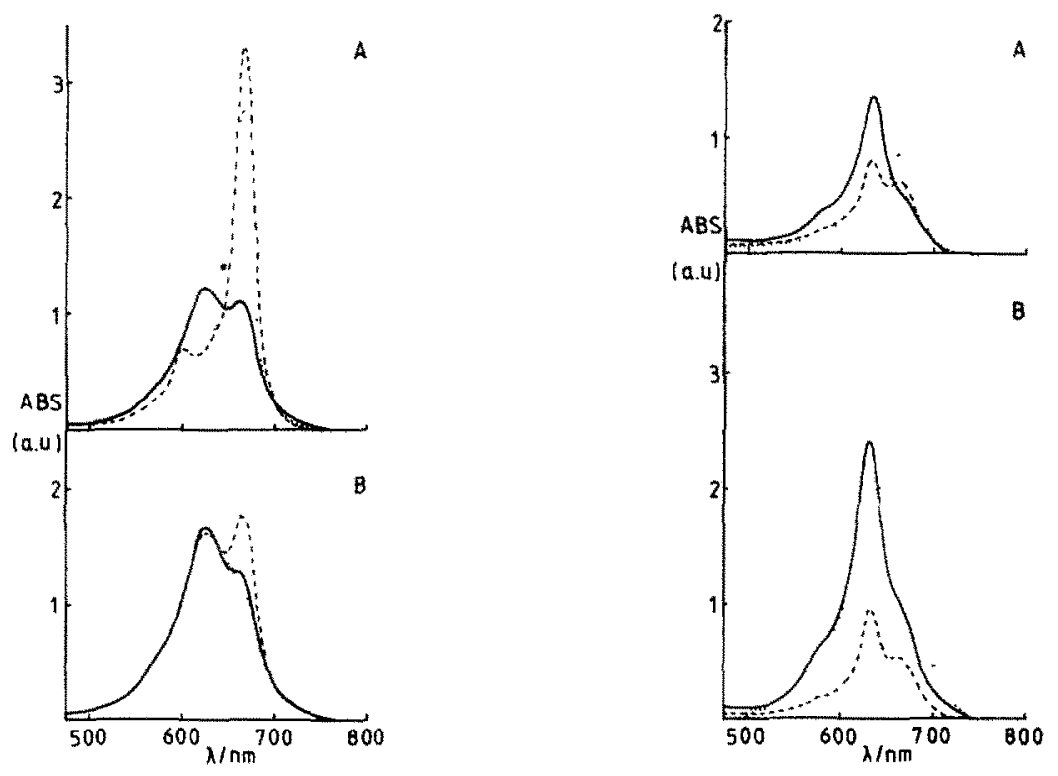

Fig. 3. UV-vis spectra for CoTSPe $\left(10^{-5} M\right)$. (A) (-) Recorded immediately after addition of CoTSPc to $0.1 M$ KOH (oxygen-free); (-- ) after 1 h of oxygen saturation; $(\cdots \cdots)$ after 1 h of oxygen saturation and then $1 \mathrm{~h}$ of helium saturation. (B) The same notation is used but the time sequence of oxygen and helium saturation has been reversed.

Fig. 4. UV-vis spectra for FerSPc $\left(10^{-5} M\right)$. For notation, see Fig. 3. 
same rate as at the beginning of the experiment. So, the rearrangement is irreversible.

In Fig. 3B, with helium first and then oxygen, the slowing down of the oxygenation is already visible. By comparing Figs. 3A and 3B, it is evident that the oxygen adduct is formed with a higher rate when the solution is directly saturated with oxygen. Although the initial conditions are slightly different (for Fig. 3B the concentration of the freshly prepared solution appeared to be somewhat higher than that for Fig. 3A, leading to relatively more dimer species in the solution), this does not influence the conclusions drawn.

For the recorded spectra of FeTSPc, it is even more difficult to draw conclusions. These experiments are complicated by the fast degradation of the complex in the presence of oxygen, as can be observed in Fig. 4. Contrary to CoTSPc, with FeTSPc an oxygen-containing species is detected immediately after the addition of FeTSPc to the oxygen-free solution. Probably, the oxygen-FeTSPc bond is so strong that oxygen is already irreversibly adsorbed on FeTSPc in the solid form.

In acid media the effects are qualitatively the same, but somewhat smaller.

\section{Concentration dependence}

In Figs. 5 (and 6) the results for three different concentrations of CoTSPc (and $\mathrm{Fe} T \mathrm{TPc}$ ) dip solutions are given. As can be concluded from these figures, increasing the concentration leads to a higher coverage.

If $n=1$ is supposed for the redox process observed for CoTSPc (Fig. 5), one can calculate the following coverages from the charge under the oxidation or reduction peak: $1.4 \times 10^{-10}, 5.5 \times 10^{-11}$ and $1.5 \times 10^{-11} \mathrm{~mol} \mathrm{~cm}^{-2}$ for concentrations of $10^{-4}, 10^{-5}$ and $10^{-6} M$, respectively. A limiting surface coverage appears to be reached with concentrations of $10^{-4} M$ or higher because this coverage $\left(1.4 \times 10^{-10}\right.$

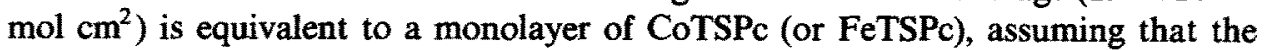
molecules lie parallel to the surface and occupy $2 \mathrm{~nm}^{2}$ per molecule.

An increase of the dip time to $1 \mathrm{~h}$ for the $10^{-6} M$ solution leads to the same coverage as that observed for the $10^{-4} M$ solution after $1 \mathrm{~min}$, indicating a
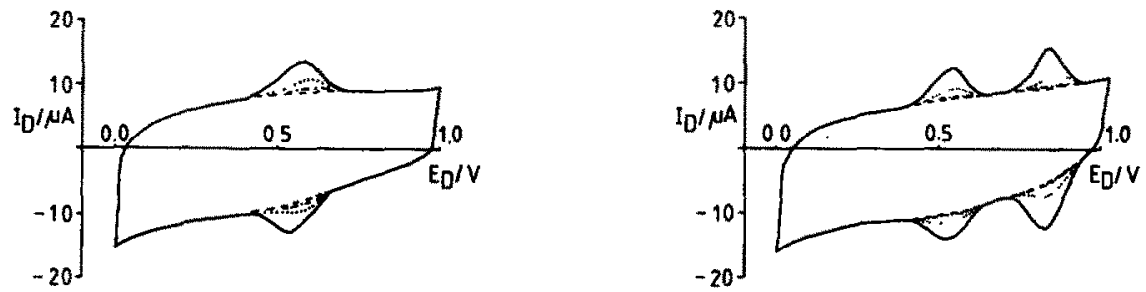

Fig. 5. Cyclic voltammograms of CoTSPc adsorbed on $\mathrm{Cp}$ from solutions of different concentrations. ( $-10^{4} M ;(\cdots \cdots) 10^{-5} M ;(\cdot-\cdot-\cdot) 10^{-6} M ;(--)$ Cp. Other specifications as in Fig. 1.

Fig. 6. Cyclic voltammograms of FeTSPc adsorbed on $\mathrm{Cp}$ from solutions of different concentrations. Specifications as in Fig. 5. 
diffusion-controlled process. However, kinetic control for the adsorption process [8] cannot be completely ruled out on the basis of these facts alone.

The cyclic voltammogram of FeTSPc adsorbed on Cp shows two redox processes (see Fig. 6). From the charges under these peaks, and again assuming a process for which $n=1$, the following coverages are calculated: $1.3 \times 10^{-10}$ and $3.5 \times 10^{-11}$ mol cm${ }^{-2}$ for $10^{-4}$ and $10^{-5} M$ solutions, respectively. For the $10^{-6} M$ solution no surface concentration is given because for this low coverage a redox peak is hardly detectable. A similar influence of the concentrations of FePc and $\mathrm{CoPc}$, dissolved in pyridine, on the adsorption process is observed.

The phenomena can be explained as follows. It has been reported $[14,15]$ that increasing the ionic strength of a solution of CoTSPc increases the dimer peak in the UV-vis spectrum. The extra ions most probably compensate the expected large electrostatic repulsion between two CoTSPc ${ }^{4-}$ ions. We now suppose that in alkaline solutions the dimerization process is followed by aggregation of the dimers. After some time, these species have grown to such dimensions that the accessibility for oxygen, and thus the oxygenation rate, is decreased. It is to be expected that aggregation does not affect the absorption behaviour, and the recorded spectra are therefore not changed. Further, we suppose that the aggregation occurs for oxygenfree species as well as for oxygen-containing species. The newly formed species show a considerably longer time for oxygen uptake or release compared with the original monomer or dimer. A possible reaction scheme is given in Fig. 7 for both CoTSPc and FeTSPc. In this scheme, the reactions with oxygen are written in the horizontal direction, while the dimerization and the aggregation are given vertically. The aggregation and the oxygenation of the aggregates occur slowly. For FeTSPc, no oxygen-free dimer is detected. The acceptable reason for this is that the equilibrium between the monomer and the dimer form lies completely on the monomer site.

In $1 \mathrm{M} \mathrm{KOH}$, the aggregation continues and after some days the tetrasulfonatophthalocyanine starts to precipitate, until finally a clear solution is obtained.

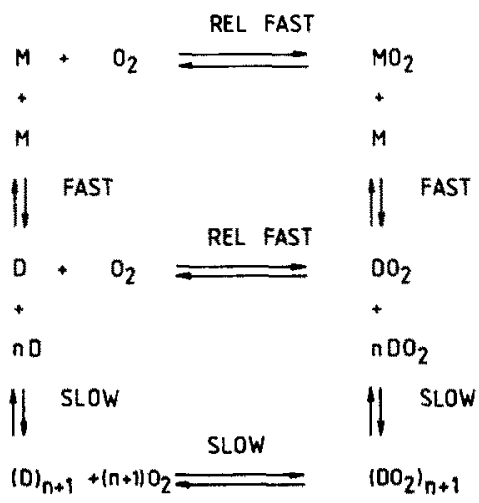

Fig. 7. Reaction scheme. $M$ is a monomer; $D$ is a dimer; $\mathrm{MO}_{2}$ and $\mathrm{DO}_{2}$ are species containing oxygen; and $(\mathrm{D})_{n+1}$ and $\left(\mathrm{DO}_{2}\right)_{n+1}$ are aggregates. 
For FeTSPc solutions, first peroxy-bridged species are formed, as can be concluded from the fact that with helium saturation a spectrum of the oxygen-free FeTSPc monomer is obtained. It is not likely that an oxo-bridged species is converted into an oxygen-free species by helium saturation alone. Besides the aggregation (as is also observed for FeTSPc in $1 M \mathrm{KOH}$ ), after some time some peroxy species are probably converted into oxo-bridged species, and this could also partly explain the observed irreversible oxygenation of FeTSPc.

The adsorption of FeTSPc on $\mathrm{Cp}$ is probably promoted in the same way as the aggregation in solution, by increasing the ionic strength of the solution. The large negative charge of the FeTSPc ring hinders the adsorption of FeTSPc on the graphite surface. By compensation of this charge by cations, adsorption of the FeTSPc molecule is made possible.

The difference between the adsorption behaviour of CoTSPc and FeTSPc leads to the conclusion that the metal centre is involved in the bonding to the graphite surface. Perhaps an association of this centre to an oxygen functionality on the graphite takes place, as has already been suggested by Zagal [7], based on the different observed coverages for the ordinary and the basal plane of pyrolytic graphite. On the latter substrate, fewer surface groups are available.

Contrary to our observations, Zecevic et al. [8] reported that the $\mathrm{pH}$ has no effect on the adsorption process of FeTSPc. In their experiments they used solutions which were prepared from stock solutions. It is evident that their solutions must have been aged. Especially with FeTSPc, we observed a drastic decrease in surface coverage of the $\mathrm{Cp}$ when solutions of several days old were used. In that case, hardly any redox peaks were detectable. The same behaviour was found with $\mathrm{FePc}$ dissolved in pyridine.

\section{(B) Oxygen reduction behaviour}

\section{Oxygen reduction on $\operatorname{CoTSP} c$}

The fact that different coverages are achieved when solutions of varying dip concentrations are used enables us to study the electrocatalysis of oxygen reduction as a function of the electrode coverages with phthalocyanines.

Figure 8 shows the oxygen reduction behaviour for the three coverages of CoTSPc, as calculated in the preceding section. As already described in a previous paper [20], the half-wave potential increases as the coverage increases. In this paper,

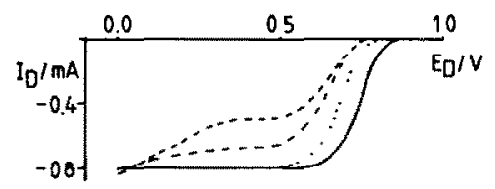

Fig. 8. Oxygen reduction at electrodes covered with different amounts of CoTSPc: $(\longrightarrow) 1.4 \times 10^{-10}$; $(\cdot \cdots \cdot) 5.5 \times 10^{-11} ;(\cdot-\cdot-\cdot) 1.5 \times 10^{-11} \mathrm{~mol} \mathrm{~cm}^{-2} ;(--)$ Cp. Electrolyte: $1 \mathrm{M} \mathrm{KOH}$, oxygensaturated; scan rate $=50 \mathrm{mV} \mathrm{s}^{-1}$; rotation frequency $=16 \mathrm{~s}^{-1}$. 

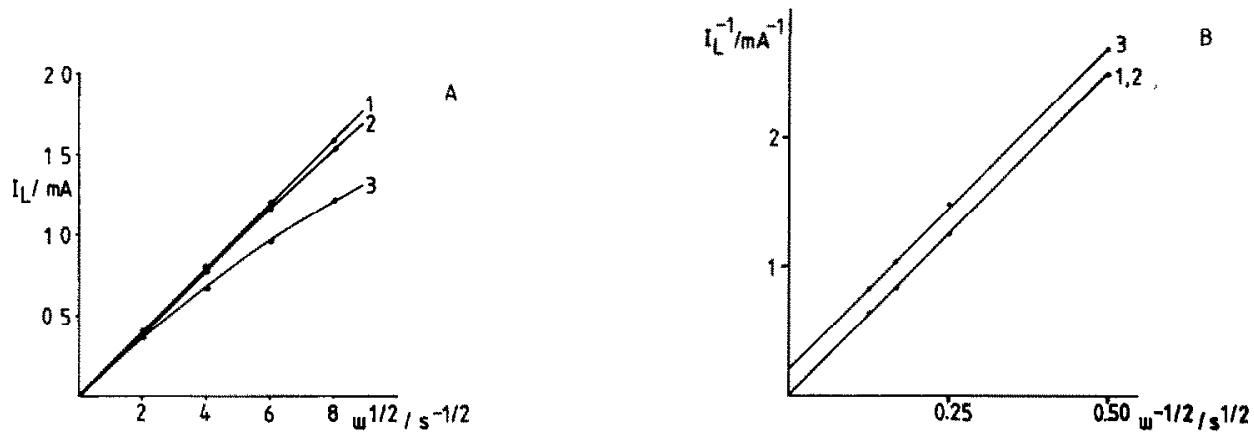

Fig. 9. Levich (A) and Koutecky-Levich (B) plots for the oxygen reduction at the electrodes of Fig. 8. Amounts of CoTSPc: (1) $1.4 \times 10^{-10}$; (2) $5.5 \times 10^{-11}$; (3) $1.5 \times 10^{-11} \mathrm{~mol} \mathrm{~cm}{ }^{-2}$.

we focus our attention on the values of the limiting current. For the electrodes with surface concentrations from $1.4 \times 10^{-10}$ to $5.5 \times 10^{-11} \mathrm{~mol} \mathrm{~cm}{ }^{-2}$, a current of 0.8 $\mathrm{mA}$ is measured in the diffusion-controlled region. This is equal to the diffusion limiting current, determined according to the Levich equation for the reduction of $\mathrm{O}_{2}$ to $\mathrm{H}_{2} \mathrm{O}_{2}$, at a rotation frequency of $16 \mathrm{~s}^{-1}$ and an electrode surface area of 0.52 $\mathrm{cm}^{2}$. The limiting currents observed for different rotation frequencies are depicted as Levich plots in Fig. 9A. For the smallest coverage, curve 3, a deviation from Levich behaviour is observed. When these results are plotted as Koutecký-Levich plots $\left(i_{1}^{-1}\right.$ vs. $\left.\omega^{-1 / 2}\right)$, in Fig. 9B, the extrapolated line for the smallest coverage (curve 3 ) does not go through the origin, indicating the occurrence of "kinetic limitation". This has been attributed, by Durand and Anson [21], to a rate-determining chemical reaction between oxygen and the catalyst. In their experiments, they used cobalt porphyrin as a catalyst. In our case, a similar explanation can be given.

However, in the case of very small coverages an alternative explanation based on a theory about surface diffusion, as has been developed by McIntyre and Peck for gold [22], is also possible. When only few catalyst molecules are present on the surface, it must be realized that approach of the electrode by an oxygen molecule does not automatically mean that an active site is encountered. According to McIntyre and Peck, "current or kinetic saturation" occurs as the time for an oxygen molecule to traverse through the convective diffusion layer becomes comparable to the time required to diffuse across the surface to an active site [22]. The thickness $(\delta)$ of the convective diffusion layer at a rotating-disc electrode (RDE) is given by $\delta=1.61 D^{1 / 3} v^{1 / 6} \omega^{-1 / 2}$

where $D$ is the diffusion coefficient of the electroactive species, $\nu$ is the kinematic viscosity of the electrolyte and $\omega$ is the rotational speed of the electrode. The time $(\tau)$ to traverse this layer can be calculated as

$\tau=1.3 D^{-1 / 3} \nu^{1 / 3} \omega^{-1}$

For curve 3 of Fig. 9 deviation of the Levich behaviour is already visible for a rotation frequency of $16 \mathrm{~s}^{-1}$. For this rotation frequency the time required to pass 
through the diffusion layer is $0.12 \mathrm{~s}$, with $\nu=1.065 \times 10^{-2} \mathrm{~cm}^{2} \mathrm{~s}^{-1}$ and $D=1.36 \times$ $10^{-5} \mathrm{~cm}^{2} \mathrm{~s}^{-1}$ [23]. The chosen onset point of the "kinetic saturation" is rather arbitrary; whereas McIntyre and Peck took the value at complete saturation, we have chosen a rotation frequency where only a small deviation of the Levich behaviour is observed. Thus, the surface diffusion time $(t)$ must be smaller than the solution diffusion time $(\tau)$ for the case of a rotation frequency of $16 \mathrm{~s}^{-1}$. Therefore, it is reasonable to assume that $t$ is in the range of $(0.01-0.1) \tau$.

When the surface diffusion is treated as a random walk, with the above-mentioned assumption, an estimate of the surface diffusion coefficient, $D_{\mathrm{s}}$, can be made from the following relation:

$\left\langle x^{2}\right\rangle=2 D_{\mathrm{s}} t$

where $\left\langle x^{2}\right\rangle$ is the mean square displacement. If it is assumed that CoTSPc is randomly distributed over the graphite surface, then a loading of $1.5 \times 10^{-11} \mathrm{~mol}$ $\mathrm{cm}^{-2}$ is equivalent to a surface domain of $11 \mathrm{~nm}^{2}$ for one CoTSPc molecule, i.e. a circle with a radius of $1.9 \mathrm{~nm}$. The time available to travel this distance is $0.0012-0.012 \mathrm{~s}$ (i.e. $1-10 \%$ of the time necessary to pass through the diffusion layer), so a surface diffusion coefficient of $1.5 \times 10^{-11}-1.5 \times 10^{-12} \mathrm{~cm}^{2} \mathrm{~s}^{-1}$ is determined. This value is in the same range as the value for the surface diffusion coefficient for a gold (111) face which has been calculated by McIntyre and Peck $\left(7 \times 10^{-11} \mathrm{~cm}^{2}\right.$ $\mathrm{s}^{-1}$ ). For both surfaces, only a weak interaction is expected to occur between oxygen and the surface [22,24]. Association of the catalyst molecules on the graphite surface will result in a higher surface diffusion coefficient. In this article, only a random distribution will be taken into account. Thus, the above-given calculation demonstrates that surface diffusion can explain the "kinetic limitation". Both explanations (a rate-determining chemical step or surface diffusion) are equally probable; the second explanation, however, has the advantage that it does not require introduction of a rate-determining chemical step.

\section{Oxygen reduction on FeTSPc}

The resulting oxygen reduction behaviour for the three different coverages is depicted in Fig. 10. It is clear that the oxygen reduction wave is composed of two different waves, as previously published by Zagal et al. [6,7,25]. When the coverage decreases, the first wave (or the wave at low overpotential) disappears more rapidly than the second wave (main wave) (see Fig. 10). For FePc, the same observations have been made [26].

The results of a study of the oxygen reduction on electrodes covered with different ammounts of FeTSPc as a function of the rotation frequency are summarized in a Levich plot (Fig. 11). The points in this figure are the obtained current maxima (see also Fig. 10). These maxima are characteristic for both FeTSPc [7] and FePc [26]. The decrease in current in Fig. 10 is caused by the competition between $\mathrm{FePc}$ (or FeTSPc) sites and the graphite surface at high overpotentials. The graphite surface itself gives hydrogen peroxide as a reduction product, and compared with the reduction of oxygen to water at FePc (or FeTSPc), this causes a decrease in the current. 

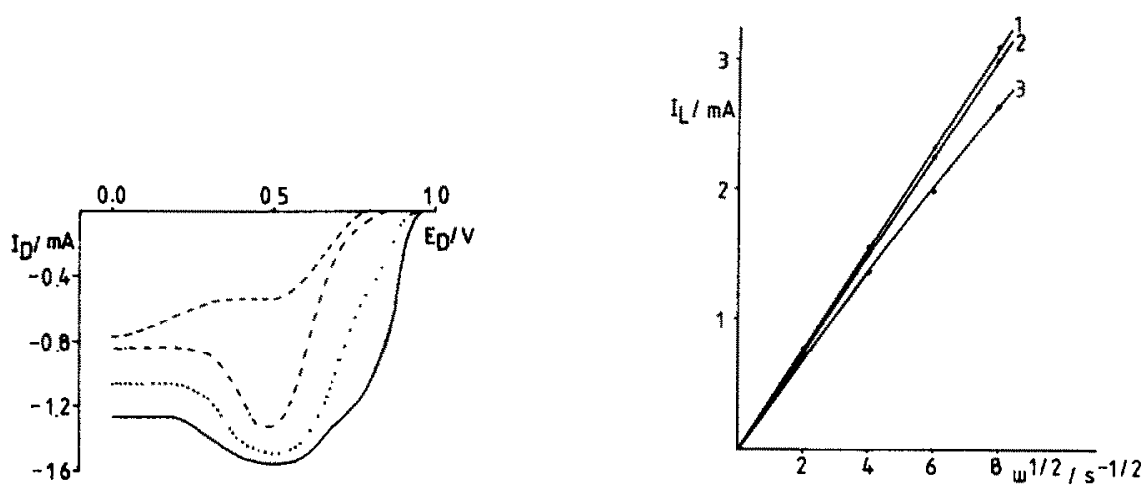

Fig. 10. Oxygen reduction at electrodes covered with different amounts of FeTSPc: $(\longrightarrow) 1.3 \times 10^{-10}$; ( …) $3.5 \times 10^{-11} \mathrm{~mol} \mathrm{~cm}^{-2} ;(\cdot-\cdot-\cdot)$ no coverage determinable; $(---)$ Cp. Other specifications as in Fig. 8.

Fig. 11. Levich plots for the oxygen reduction at electrodes covered with the same amounts of FeTSPc as those in Fig. 10. (1) $1.3 \times 10^{-10}$; (2) $3.5 \times 10^{-11} \mathrm{~mol} \mathrm{~cm}{ }^{-2}$; (3) no coverage determinable.

Curves 1 and 2 in Fig. 11 demonstrate that the oxygen reduction at the two highest coverages satisfy the Levich equation, while for the other case, curve 3 , a deviation of this behaviour is observed. The diffusion limiting currents are a factor of two higher for FeTSPc than for CoTSPc because of the oxygen reduction to water at FeTSPc instead of hydrogen peroxide. When the results are plotted in a Koutecký-Levich plot, we obtain, as in Fig. 9B for CoTSPc, parallel lines, of which the line for the smallest coverage does not pass through the origin, again indicating "kinetic limitation". The same explanations as before for CoTSPc are now possible.

If the FeTSPc coverage of the electrode decreases, then the prewave shows more severe "kinetic limitation" than the main wave, as can be concluded from Fig. 10. For this kinetic limitation an explanation based on surface diffusion is also possible, but here the conclusion must be drawn that we are dealing with two different FeTSPc sites. One type of site is then responsible for the main wave, while the other, present in a minority, should produce the prewave.

The possibility of the existence of two different sites (monomeric and dimeric) has been suggested by us earlier and was based on analogies [26]. A survey of the literature shows that direct reduction of oxygen to water without the formation of hydrogen peroxide as an intermediate occurs on noble metals such as platinum and silver [27], electrodes prepared by UPD of some metals [28] and cofacial dicobalt porphyrins [29]. In all these cases, this behaviour is explained assuming bridge adsorption. For FeTSPc (or FePc), direct reduction of oxygen occurs at low overpotentials, as is demonstrated by the fact that in rotating ring-disc electrode (RRDE) experiments no ring current due to the production of hydrogen peroxide is detected at the potentials of the prewave [25]. As stated previously, the prewave must be associated with dimer sites for which bridge adsorption of oxygen is possible, while the main wave is due to monomer sites. 

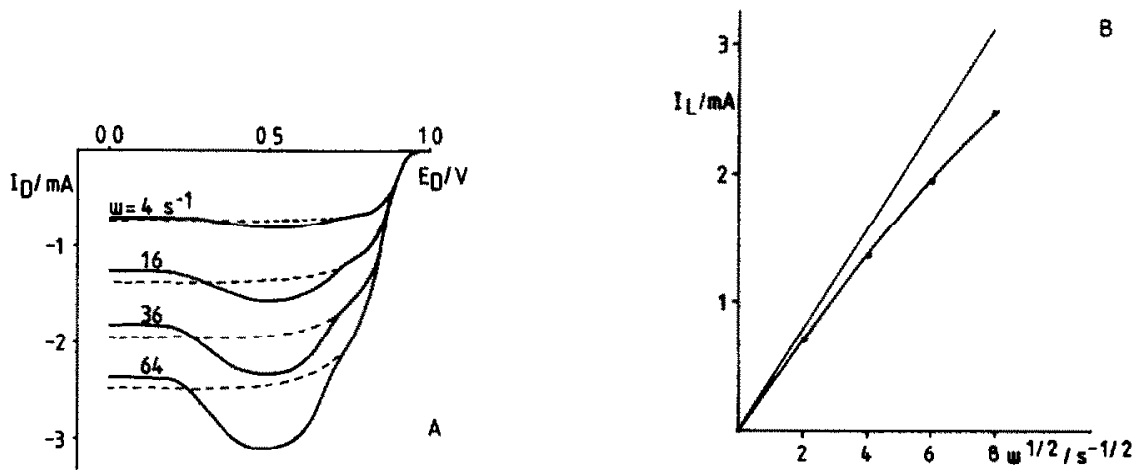

Fig. 12. (A) Oxygen reduction at FeTSPc adsorbed on $\mathrm{Cp}$ for the highest coverage $\left(1.3 \times 10^{-10} \mathrm{~mol}\right.$ $\mathrm{cm}^{-2}$ ) only. The rotation frequencies are given in the figure. The dashed lines represent the extrapolations of the prewave. Other specifications as in Fig. 8. (B) Levich plots for the extrapolated prewave. The straight line also drawn in this figure is the Levich behaviour of the current maxima for the highest coverage (see also Fig. 10, line 1).

The oxygen reduction behaviour at the highest coverage of FeTSPc is given for four different rotation frequencies in Fig. 12A. In this figure an extension of the prewave is also constructed (dashed lines). Of course, this extrapolation is questionable, but the extrapolated curves show the onset of "kinetic limitation" (see Fig. 12B) and this agrees with the fact that the prewave depends rather critically on the coverage. In Fig. 12B, deviation of the Levich equation for a rotation frequency from $16 \mathrm{~s}^{-1}$ onwards is observed. If again the assumption is made that for this rotation frequency the time required for the surface diffusion is $10 \%$ of the time necessary to pass through the diffusion layer, then a time of $0.012 \mathrm{~s}$ is available for surface diffusion. In this time, a distance of $1.9 \mathrm{~nm}$ could be covered according to eqn. (3) when a surface diffusion coefficient of $1.5 \times 10^{-12} \mathrm{~cm}^{2} \mathrm{~s}^{-1}$ is used. From this distance, it can be calculated that, in the case of a uniform distribution of the sites over the surface, the coverage is $1.5 \times 10^{-11} \mathrm{~mol} \mathrm{~cm}{ }^{-2}$. Compared with the total amount of $1.3 \times 10^{-10} \mathrm{~mol} \mathrm{~cm}{ }^{-2}$ of FeTSPc present on the surface, this corresponds to $12 \%$ of it. Taking $1 \%$ of the time necessary to pass through the diffusion layer as the surface diffusion time, then the corresponding surface diffusion coefficient of $1.5 \times 10^{-11} \mathrm{~cm}^{2} \mathrm{~s}^{-1}$ must be used and the same amount of dimer sites is calculated.

To prove the existence of dimer sites, independent evidence is necessary. Unfortunately, it is not possible to carry out reflectance spectroscopy with electrodes made of ordinary pyrolytic graphite because the surface of these electrodes is not reflective enough. Reflectance spectroscopy has been performed by Nikolic et al. [12] on the basal plane of pyrolytic graphite, which shows a higher reflectivity. However, this basal plane pyrolytic graphite does not behave identically to ordinary pyrolytic graphite. Zagal, for example, reported an almost completely vanished prewave [7]. Going from ordinary to basal plane pyrolytic graphite, the coverage has 
decreased four to five times. From the dramatic effect on the prewave of a three to four times decrease in coverage, as can be seen in Fig. 10, we can imagine that the prewave completely vanishes when the basal plane instead of ordinary pyrolytic graphite is used. Perhaps, there is also an influence of the surface roughness on the probability of the occurrence of dimer sites, as has been suggested in a previous publication [26].

As to the results of Nikolic et al. for the basal plane, they recorded spectra at a potential of $0.9 \mathrm{~V}$ (vs. RHE), where the adsorbed FeTSPc molecule is in the oxidized Fe(III) state (see Fig. 2). The spectrum shows a main peak at $635 \mathrm{~nm}$, ascribed to a dimer species. However, it may also be argued that the peak corresponds to a monomeric $\mathrm{Fe}$ (III) TSPc species which has almost the same absorption wavelength $(632 \mathrm{~nm})$ as an oxygen-containing dimer in the solution [30]. Experiments are planned to solve this question by studying the spectra at potentials below $0.9 \mathrm{~V}$, where the Fe ion is in the Fe(II) state. For the moment, we will take the dimer model of Nikolic et al. as valid. In their view, a structure with the phthalocyanine rings perpendicular to the surface belongs to the possibilities. Some evidence for this model has been obtained from Raman spectroscopy [10,31].

The estimate of $12 \%$ dimer sites seems to be in contradiction with the spectroscopic results. We must keep in mind, however, that for each dimer site there are two monomer sites available. Between two molecules bridge adsorption can occur, while outside the region between the two molecules two places remain for the formation of monomeric oxygen adducts. So, even if we are only dealing with FeTSPc dimers and assuming that the adsorption model of Nikolic et al. is valid, we must keep in mind that bridge adsorption occurs on only $33 \%$ of the available sites. The estimated number of $12 \%$ should be considered as an indication of the value which can be expected for the amount of dimers; so, an agreement with the results of Nikolic et al. is still possible.

The model presented here explains the observed "kinetic limitation" for the prewave solely by the small number of dimer sites. The advantage with respect to other models is that there is no need to introduce a rate-determining chemical step.

\section{FePc compared with FeTSPc}

Up to now, no distinction has been made between CoTSPc (or FeTSPc) and $\mathrm{CoPc}$ (or $\mathrm{FePc}$ ) in the observed cathodic oxygen reduction behaviour. The differences between $\mathrm{CoPc}$ and $\mathrm{COTSPc}$ are so small that they can be neglected. However, although most results are qualitatively also the same for FeTSPc and FePc, there are some differences which require a closer examination.

The previously published results obtained for FePc, irreversibly adsorbed on graphite, from a pyridine solution [26], are repeated in Fig. 13. First of all, it must be noted that with $\mathrm{FePc}$, slightly higher coverages are obtained compared with FeTSPc. The coverages for FePc, calculated in the same manner as for FeTSPc, are $1.6 \times 10^{-10}$ and $2 \times 10^{-11} \mathrm{~mol} \mathrm{~cm}{ }^{-2}$ for $10^{-3}$ and $10^{-4} M$ solutions, respectively. For the $10^{-5} M$ solution, no peaks are detected.

In the potential region of the prewave, hardly any differences are observable 

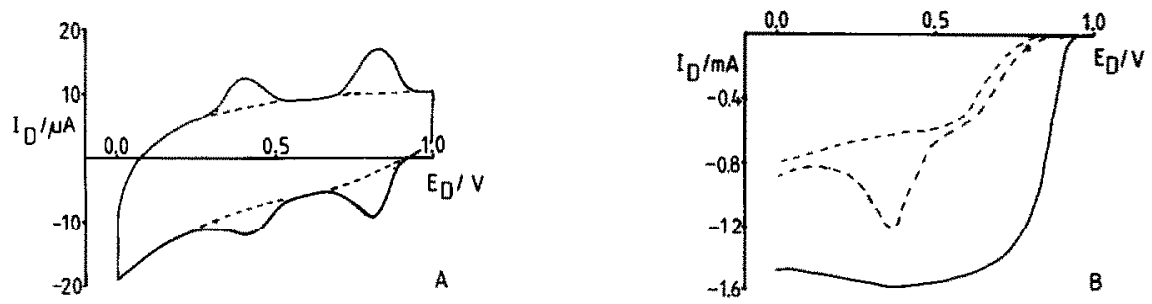

Fig. 13. (A) Cyclic voltammograms of FePc adsorbed on $\mathrm{Cp}$ from pyridine solutions of different concentrations. (- $10^{-3} M ;(\cdots \cdots) 10^{-4} M ;(\cdot-\cdot-\cdot) 10^{-5} M ;(---)$ Cp. Other specifications as in Fig. 1. (B) Oxygen reduction at the electrodes of (A). Other specifications as in Fig. 8.

(Figs. 10 and 13). Perhaps, due to the slightly higher coverage for FePc, less "kinetic limitation" occurs in the case of a $10^{-3} M$ FePc solution compared with a $10^{-4} M$ FeTSPc solution. The observed current maxima in the $i-E$ curves for the oxygen reduction are shifted ca. $100 \mathrm{mV}$ in the negative direction, going from FeTSPc to FePc. This shift is not due to a difference in coverage because Figs. 10 and 13 for FeTSPc and FePc, respectively, show that this maximum does not shift as the coverage is altered. A comparison of the cyclic voltammograms measured for FePc and FeTSPc in oxygen-free electrolytes leads to the conclusion that the shift of the current maximum is accompanied by a shift in the potential for the second, most negative, redox process. These results concur with the statement made by Zagal et al. that the current maximum is associated with the second redox process [25].

It is amazing that the sulfonation of the ligand has such a great effect on the redox potentials, as observed for the metal chelates. The reason why only the most negative redox process is affected is not completely understood, especially if one ascribes both redox processes to the central metal ion, as is done by Zecevic et al. [8].

Further investigations are necessary to explain the difference in the redox behaviour between FeTSPc and FePc, and to draw conclusions about the way the complexes adsorb on the electrode. We hope that this will lead to more insight into the mechanism of oxygen reduction on FeTSPc or FePc irreversibly adsorbed on pyrolytic graphite.

\section{ACKNOWLEDGEMENTS}

The present investigations were carried out with the support of the Netherlands Foundation for Chemical Research (S.O.N.) and with financial aid from the Netherlands Organization for the Advancement of Pure Research (Z.W.O.).

\section{REFERENCES}

1 R.J.H. Chan, Y.O. Su and T. Kuwana, J. Inorg. Chem., 24 (1985) 3777.

2 A. Bettelheim, R.J.H. Chan and T. Kuwana, J. Electroanal. Chem., 99 (1979) 391. 
3 R.R. Durand and F.C. Anson, J. Electroanal. Chem., 134 (1982) 273.

4 N. Kobayashi, M. Fujihira, T. Osa and S. Dong, Chem. Lett., (1982) 575.

5 J.H. Zagal, R.K. Sen and E. Yeager, J. Electroanal. Chem., 83 (1977) 207.

6 J.H. Zagal, M. Pacz, J. Sturm and S. Ureta-Zanartu, J. Electroanal. Chem., 182 (1984) 295.

7 J.H. Zagal, Thesis, Case Western Reserve University, Cleveland, 1978.

8 S. Zecevic, B. Simic-Glavaski and E. Yeager, J. Electroanal. Chem., 196 (1985) 339.

9 D. Ozer, R. Parash, F. Broitman, U. Mor and A. Bettelheim, J. Chem. Soc., Faraday Trans. 1, 80 (184) 1139.

10 B. Simic-Glavaski, S. Zecevic and E. Yeager, J. Phys. Chem., 87 (1983) 4555.

11 B. Simic-Glavaski, S. Zecevic and E. Yeager, J. Electroanal. Chem., 150 (1983) 469.

12 B.Z. Nikolic, R.R. Adzic and E.B. Yeager, J. Electroanal. Chem., 103 (1979) 281.

13 I. Collamati, Inorg. Chim, Acta, 35 (1979) 303.

14 L.C. Gruen and R.J. Blagrove, Aust. J. Chem., 26 (1973) 319.

15 D.M. Wagnerova, E. Schwertnerova and J. Veprek-Siska, Collect. Czech. Chem. Commun., 39 (1974) 1980.

16 B.J. Kennedy, K.S. Murray, P.R. Zwack, H. Homborg and W. Kalz, Inorg. Chem., 24 (1985) 3302.

17 R.D. Harcourt, J. Inorg. Nucl. Chem., 39 (1977) 243 and refs. cited therein.

18 T.D. Smith and J.R. Pilbrow, Coord. Chem. Rev., 39 (1981) 295.

19 J.H. Weber and D.H. Busch, J. Inorg. Chem., 4 (1965) 469.

20 A. Elzing, A. van der Putten, W. Visscher and E. Barendrecht, J. Electroanal. Chem., 200 (1986) 313.

21 R.R. Durand and F.C. Anson, J. Electroanal. Chem., 134 (1982) 273.

22 J.D.E. McIntyre and W.F. Peck, Jr., Proc. Electrochem. Soc. (Chem. Phys. Electrocatal.), 84 (1984) 102.

23 K.E. Gubbins and R.D. Walker, Jr., J. Electrochem. Soc., 112 (1965) 469.

24 A.V. Kiselev, Q. Rev. Chem. Soc., 15 (1961) 99.

25 J. Zagal, P. Bindra and E. Yeager, J. Electrochem. Soc., 127 (1980) 1506.

26 A. van der Putten, A. Elzing, W. Visscher and E. Barendrecht, J. Electroanal. Chem., 214 (1986) 523.

27 P. Fischer and J. Heitbaum, J. Electroanal. Chem., 112 (1980) 231.

28 K. Jüttner, Electrochim. Acta, 29 (1984) 1597.

29 J.P. Collman, M. Marocco, P. Denisevich, C. Koval and F.C. Anson, J. Electroanal. Chem., 101 (1979) 117.

30 D. Vonderschmitt, K. Barnauer and S. Fallab, Helv. Chim. Acta, 48 (1965) 951.

31 R. Adzic, B. Simic-Glavaski and E. Yeager, J. Electroanal. Chem., 194 (1985) 155. 